\title{
Correspondence
}

\section{Modified Blalock-Taussig operation using polytetrafluoroethylene (Impra) grafts}

Sir,

In reply to the letter by J J Rossouw (1984; 51: 237), P H Kay et al (p 238) state that the resistance of a subclavian to pulmonary artery shunt $3 \mathrm{~cm}$ long and 4 $\mathrm{mm}$ in diameter is not a limitation to the flow into the lung, and that if the pulmonary resistance is very high this may act as a limitation itself. They also say that the subclavian artery must remain the limiting factor (to flow).

The resistance of a $3 \mathrm{~cm} \times 4 \mathrm{~mm}$ graft is, from their figures, $1.16 \times 10^{9} \mathrm{Nm}^{-5} \mathrm{~s}$ while the resistance of the normal lung to steady flow falls from a value of $2 \times 10^{9} \mathrm{Nm}^{-5}$ s (15 PRU) at birth ${ }^{1}$ to approximately $1.7 \times 10^{9}$ at the age of 3 weeks. ${ }^{2}$ Although the pulmonary vascular resistance value of patients requiring Blalock-Taussig shunts is probably not normal, it is clear from these figures that only during the first few days of life is the pressure drop across the graft and across the lung comparable in magnitude.

If the resistance of the lung falls, as it will in normal children, the resistance of the graft becomes progressively more important as a limitation to flow in the lung. If the graft is too large the pressure drop across it will be too small and the lungs will be overperfused. The volume flow to the lungs should, however, increase during growth and development so the largest graft consistent with controlling overperfusion should be used.

Having decided what the required mean flow to the lung is, the surgeon should select the dimensions of the graft so that, ideally, the mean pressure will fall from systemic to pulmonary values in traversing the graft alone.

\author{
S E Greenwald, \\ C L Berry, \\ Department of Morbid Anatomy, \\ The London Hospital, \\ London E1 1BB.
}

References

1 Arcilla RA, Oh W, Wallgren G, Hanson JS, Gessner IH,
Lind J. Quantitative studies of the human neonatal circulation. 2. Hemodynamic findings in early and late clamping of the umbilical cord. Acta Paediatr Scand 1967; suppl 179: 23-42.

2 Lucas RV Jr, St Geme JW Jr, Anderson RC, Adams P $\mathrm{Jr}$, Ferguson DJ. Maturation of the pulmonary vascular bed. Am f Dis Child 1961; 101: 467-75.

This letter was shown to the authors, who reply as follows:

Sir,

Dr Greenwald and Professor Berry calculate the resistance of a $3 \mathrm{~cm} \times 4 \mathrm{~mm}$ graft at $1 \cdot 16 \times 10^{9} \mathrm{Nm}^{-5} \mathrm{~s}$ and point out that this is the same order of magnitude as the pulmonary vascular resistance in the normal child. Extrapolating this concept of two resistances in series they suggest that the surgeon should "select the dimensions of the graft so that, ideally, the mean pressure will fall from systemic to pulmonary values traversing the graft alone." This is in agreement with clinical experience which shows that when the resistance in the aortopulmonary anastomosis is low-for example, a large Waterson shunt-then excessive pulmonary blood flow is a problem.

Anatomical studies show, however, an increase in the smooth muscle component of the pulmonary arterioles in neonates with cyanotic congenital heart disease. Thus the pulmonary vascular resistance of this group of patients is unlikely to be normal. Furthermore, it is exceedingly difficult to calculate either before the shunt, when there is a large central cardiac resistance to pulmonary blood flow, or after the shunt, when the dual source of pulmonary blood flow and the possibility of different pressures in the two lungs make errors likely. ${ }^{1}$

Thus the pulmonary vascular resistance remains unknown, preventing the pressure component of Greenwald and Berry's equation from being calculated. Furthermore, the pulmonary vascular resistance may change with the growth of the child and the development of the pulmonary vascular bed. Also, the resistance of the graft will change as its dimensions 
become narrowed by neointimal hyperplasia, particularly at the anastomotic site. ${ }^{2}$

Once again we return to our original conclusion (shared by Dr Rossouw; 1984; 51: 237) of choosing the largest possible graft that can be tailored to the anatomy.

P H Kay,

R E Franks,

A Capuani,

C Lincoln,

\section{Chordal rupture: aetiology and natural history}

Sir,

We read with interest the recent review of chordal rupture from the Brompton Hospital (1983; 50: 3127). Primary "idiopathic" rupture accounted for a large majority of cases. We wish to draw attention to the possibility that some of these patients may have had mitral valve prolapse. This possibility cannot be excluded by the slight male predominance observed in this series of patients with chordal rupture. Although mitral valve prolapse is characterised by female predominance, some complications may be selective. Moreover, other biases may operate in a retrospective series.

In reviewing 134 patients with mitral valve prolapse we have found $15(11.2 \%)$ patients with echocardiographic signs of chordal rupture. ${ }^{1}$ In another series $7 \%$ of patients with mitral valve prolapse were found to have chordal rupture. ${ }^{2}$ We have since extended our series to include 264 patients with this condition. These patients were free of other cardiovascular or systemic disorders. Twenty eight (10.6\%) patients were found to have $M$ mode echocardiographic signs of chordal rupture. The majority of these patients had three or more echocardiographic signs of chordal rupture simultaneously, a feature which enhances the sensitivity and specificity of the echocardiographic diagnosis. ${ }^{1}$ In 24 patients the diagnosis was confirmed by cross-sectional echocardiography. Only eight patients had symptoms of sufficient severity to warrant intervention, and in all of these confirmation was obtained at operation. Of particular note were three patients who had previously been followed up for mitral valve prolapse and who later developed echocardiographic signs of chordal rupture. We were also surprised to note the appreciable proportion of patients who were asymptomatic or had only mild symptoms indistinguishable from those with uncomplicated mitral valve prolapse. Of related interest is a recent necropsy series of 90 patients with mitral valve prolapse. ${ }^{3}$ Twenty two patients were found to have chordal rupture, only five of whom had related
Brompton Hospital,

London SW3 6HP.

\section{References}

1 Norberg WJ, Tadavarthy M, Knight L, Nicoloff DM, Moller JH. Late hemodynamic and angiographic findings after ascending aorta-pulmonary artery anastomosis. I Thorac Cardiovasc Surg 1978; 76: 345-52.

2 Kay PH, Capuani A, Franks RE, Lincoln C. Experience with the modified Blalock-Taussig operation using polytetrafluoroethylene (Impra) grafts. Br Heart $\mathcal{F} 1983$; 49: 359-63.

endocarditis. Thus $17(18 \%)$ patients had chordal rupture with mitral valve prolapse as the only associated cardiac lesion. In most of these patients the diagnosis of chordal rupture had not been suspected before death. Although findings in necropsy series cannot be simply extended to a patient population in a cardiac clinic, the findings corroborate our impression that chordal rupture may be more prevalent than is commonly thought and that it is often unsuspected clinically.

Many reviews of chordal rupture are of retrospective surgical series. They thus lack detailed analyses of long term clinical history and previous findings including echocardiography. They are also biased in view of the necessary selection of severely symptomatic patients who require surgery. Many of the medical reviews of spontaneous chordal rupture are from a period in which mitral valve prolapse was not an established diagnosis and before echocardiographic signs of chordal rupture had been elaborated. They may thus also obscure the underlying conditions predisposing to chordal rupture and tend to be biased towards patients with significant symptoms and signs.

Although association does not prove causality, we believe our findings are suggestive. Future reviews of chordal rupture should attempt to exclude mitral valve prolapse before designating cases as "idiopathic" or primary. This subgroup of patients may possibly become smaller. An aetiological relation between mitral valve prolapse and chordal rupture will be shown by a prospective follow up of patients with mitral valve prolapse and suitable control subjects.
G Alpan,
E Grenadier,
A Palant,
Coronary Care Unit,
Department of Cardiology,
Carmel Hospital,
PO Box 7222, Mt Carmel, Haifa, Israel. 